\title{
SupPorting LOCATION FACTORS TOWARDS SALAK Agroindustrial DEVELOPMENT IN SLEMAN AgROPOLITAN DisTRICT
}

\author{
Abimanyu Putra Azhari \\ PROGRAM STUdi PERENCANAAN WILAYAH DAN KotA, \\ JURUSAN ARSITEKTUR, FAKULTAS TEKNIK \\ Universitas SEbELAS Maret, SURAKarta \\ KUSUMASTUTI \\ PROGRAM STUDIPERENCA NAAN WILAYAH DANKOTA, \\ JURUSANARSITEKTUR, FAKULTASTEKNIK \\ UNIVERSITASSEBELASMARET, SURAKARTA \\ ISTI ANDINI \\ Program StUdiPERENCANAANWILAYAH DAN KotA, \\ JURUSAN ARSITEKTUR, FAKULTAS TEKNIK \\ UNIVERSITASSEBELASMARET, SURAKARTA
}

\begin{abstract}
Agropolitanconsept is developed as critics of industrial development failure in several Asian development countries which caused by high urbanization, unequal incomeand depletion of resources (Friedmann and Douglass, 1975). This consept also emphasize in agroindustrial development as part of successful agropolitan. Slemanagropolitan district has developed competitive commodites such as salak which can be process to high value products. AfterSlemanAgropolitan District established, the agroindustrial development still has not give the contribution for it. Many industries have limited quantity and there is no connection among other industries, so the industries just walked by itself. Many of them do not observe the important thing on their development, like location. Location has an important role for sustaining agroindustrial development.

Based on this issues, the research goal is the achievement value of supporting location factors to salakagroindustrial development in SlemanAgropolitan District. The method is scoring analysis in every location factors variable in agroindustrial development to find the value achivement of supporting location factors.

The result of this research, location factors have strongly support for salakagroindustrial development in SlemanAgropolitan District. Raw identified through origin, distance and how to gather the raw has value $96,4 \%$ which means strongly support. Labour identified through quantity, origin and distance has value 66,9\% which means support. Market identified through origin, distance and how to distribute has value 90,6\% which means strongly support. Transportation/accesibility identified through road, transportation cost and time has value $84,2 \%$ which means strongly support. Land identified through topography and disasten vulnerability has value $97,5 \%$ which means strongly support for agroindustrial development.
\end{abstract}

Keywords:agropolitan, agroindustrial development, location factor

\section{PENDAHULUAN}

Konsepagropolitanmerupakankonsep yang dikembangkansebagaikritikataskegagal anpengembanganindustri
beberapanegaraberkembangAsia yang mengakibatkankecenderunganurbanisas itinggi, ketidakmerataanpendapatan, kekuranganbahanpangan, 
pengurasandanrusaknyasumberdayaala m(Friedman dan Douglas 1975). Konsepinimenekankanpadapengembang anagroindustrisebagaiintidarikonsepagr opolitan yang merupakansalahsatubagiandarikeberhas ilanagropolitan.

KabupatenSlemanmerupakansalahsat uwilayah yang dikembangkansebagaikawasanagropolit anditetapkanmenurut SK Bupati No. $110 / \mathrm{KDH} / \mathrm{A}$ 2004dengankomoditasunggulansalak yang meliputiKecamatanTuri, sebagianTempeldanPakem.

(BappedaKabupatenSleman, 2013).

Pascaditetapkansebagaikawasanagro politan, pengembanganagroindustrisalak di

KawasanAgropolitanKabupatenSlemanm asihbelummemberikandampakbagipeng embangankawasan. $\mathrm{Hal}$ inidapatdiketahuidarimasihterbatasnyain dustri yang berkembangdantidakteraglomerasiantar asatuindustridenganindustrilainnya.

Agroindustri yang sudahadamasihberjalansendirisendiritanpamemperhatikanaspekpentin gdalampengembangannya, salahsatunyaadalahfaktorlokasi.

Lokasimemilikiperanpentingbagikeberla ngsunganindustrisuatukawasansehingga dapatberjalan optimal.

Berdasarkanisutersebut, rumusanpermasalahandaripenelitianinia dalahbagaimanaketercapaiandukunganf aktorfaktorlokasiterhadappengembanganagro industrisalak di KawasanAgropolitanKabupatenSleman?

\section{METODE}

Ruanglingkupwilayahdalampenelitiani nimeliputikawasanagropolitanKabupaten Sleman, yang terdiriatasKecamatanTuri, sebagianTempeldanPakem.

Sedangkanruanglingkupsubstansimelipu tifaktor-faktorlokasi yang berkaitanterhadappengembanganagroin dustri, sepertibahanbaku, tenagakerja, pemasaran, transportasi/ aksesibilitasdanfisiklahan.

Penelitianinimenggunakanmetodeanal isadeskriptifdananalisisskoring. Analisis tersebutdapat dijabarkan, antara lain: (1) Mengidentifikasi karakteristik pengembangan agroindustri salak di Kawasan Agropolitan Kabupaten Sleman dengan teknik analisis deskriptif kualitatif yaitu menggambarkan fenomena yang terjadi di lapangan; (2) Mengidentifikasi faktor-faktor lokasi dalam pengembangan agroindustri salak di Kawasan Agropolitan Kabupaten Sleman dengan teknik analisis deskriptif kuantitatif yaitu mendeskripsikan data berdasarkan jumlah responden yang diteliti menurut kriteria pada masingmasing variabel dan sub variabel; (3) Menganalisis dukungan faktor-faktor lokasi terhadap pengembangan agroindustri salak di Kawasan Agropolitan Kabupaten Sleman dengan analisis skoring.Kriteria skoring dirumuskan ke dalam beberapa kategori pada tabel berikut (lampiran l).

\section{HASIL DAN PEIMBAHASAN}

Karakteristik Pengembangan Agroindustri Salak di Kawasan Agropolitan Kabupaten Sleman

Agroindustri salaktersebarpadatiaptiapdesa

KawasanAgropolitanKabupatenSleman yang berjumlah 40 kelompokagroindustri. Proses kegiatanagroindustrimeliputikegiatanpra pengolahandanpascapengolahan. Kegiatanprapengolahanmeliputikegiatan menghimpundanmenyortirbahanbaku yang dibutuhkan. Sedangkankegiatanpascapengolahanmel iputipengepakkandanpemasaranproduk. Dilihatdaristrukturruangnya, 
Abimanyu P A dkk, Dukungan Faktor Lokasi...

sistemagroindustrisalakdapatdijelaskand alampetaberikutini(lampiran 2).

Faktor-faktorLokasidalamPengembangan Agroindustri Salak di KawasanAgropolitanKabupatenSleman.

Faktor-

faktorlokasidalampengembanganagroin dustrisalakmeliputibahanbaku, tenagakerja, pemasaran, transportasi/ aksesibilitasdanfisiklahan. Bahanbaku yang digunakanuntukagroindustriberasaldarid alamkawasan (bersifatlokal) denganjarakkurangdari $5 \mathrm{~km}$ yang dihimpundariprodusenmaupunpedagang / perantara. Tenagakerja yang digunakanberasaldaripermukiman di sekitarlokasiagroindustridengan ratarata penyerapan 2-6 orang per kelompok.

Pemasaranprodukagroindustriberada di dalamdan di luarkawasanAgropolitan yang tersebarpadalokasiwisata, tokooleh-olehdan di lokasiagroindustriitusendiri.

Produkagroindustrididistribusikanlangsu ngkekonsumenmaupunmelaluipedagang / perantara. Transportasi/ aksesibilitaskawasanmemilikikondisijari nganjalan yang baikdanwaktutempuh $1 / 2$ 1 jam perjalanan. Biayatransportasi yang dikeluarkandidominasiolehbiayatranspo rtasibahanbakusehinggaagroindustrilebi hberorientasikebahanbaku.

Fisiklahankawasansudahmendukunguntu kpengembanganagroindustri. $\mathrm{Hal}$ tersebutdapatdiketahuidarisemuaagroin dustriberada di kelerengan 3-8\%. Namunbeberapaagroindustriberadapada zona KRB II sehinggaperludiperlukanantisipasiterha dapbencana, terutamabencana G. Merapi.

Dukungan Faktor Lokasi terhadap Pengembangan Agroindustri Salak di Kawasan Agropolitan Kabupaten Sleman
Berdasarkanhasilanalisisdengantekn ikskoringdapatdiinterpretasikanvariabel bahanbaku yang diidentifikasimelalui sub variabelasal, jarakdancaramenghimpunbahanbakume milikinilaiketercapaiandukungan $96,4 \%$ yang

artinyasangatmendukungpengembangan agroindustri. Variabeltenagakerja yang diidentifikasimelaluisub variabeljumlah, asaldanjaraklokasitenagakerjamemilikini laidukungan $\quad 66,9 \% \quad$ yang artinyamendukungpengembanganagroin dustri. Variabelpemasaran yang diidentifikasimelalui sub variabellokasi, jarakdancaradistribusiprodukmemilikinil aiketercapaian $\quad 90,6 \% \quad$ yang artinyasangatmendukungpengembangan agroindustri. Variabeltransportasi/ aksesibilitas yang diidentifikasimelalui sub variabeljaringanjalan, biayatransportasi (cost) danwaktutempuhmemilikinilaiketercapai an $84,2 \%$ yang artinyasangatmendukungpengembangan agroindustri. Variabelfisiklahan yang diidentifikasimelalui sub variabeltopografidankerawananbencana memilikinilaiketercapaian $97,5 \%$ yang artinyasangatmendukungpengembangan agroindustri.

\section{KESIMPULAN}

Dari hasilpembahasan, faktorfaktorlokasimemilikiketercapaiandukung an yang tinggiterhadappengembanganagroindus trisalak

KawasanAgropolitanKabupatenSleman. Bahanbakumemilikiketercapaiandukung ansangattinggiterhadappengembangana groindustrikarenadidukungolehlokasi, jarak, caramenghimpunbahanbaku yang memadai.

Tenagakerjamemilikiketercapaiandukun gantinggiterhadappengembanganagroin dustrikarenadidukungolehlokasidanjarak tenagakerja. 
Namuntidakdidukungolehpenyerapanten agakerjakarenamasihtergolongrendah. Pemasaranmemilikiketercapaiandukung an yang sangattinggiterhadappengembanganagr oindustrikarenadidukungolehjarakpasar dancaradistribusiproduk.

Namunkurangdidukungolehlokasipasard ikarenakanjangkauanpasar yang masihrendah. Transportasi/ aksesibilitasmemilikiketercapaiandukun gansangattinggikarenadidukungbiayatra nsportasi (cost) danwaktutempuh. Namunkurangdidukungolehjaringanjalan dikarenakankapasitasjalan yang kurang. Fisiklahanmemilikiketercapaiandukunga nsangattinggikarenadidukungolehkondis itopografidankerawananbencana

\section{REFERENSI}

BappedaKabupatenSleman, 2013. Roadmap PenguatanSistemInovasi Daerah

KabupatenSlemanTahun 2014-2019. Pemerintah Daerah

KabupatenSleman

Friedman, John and Mike Douglas 1975.

PengembanganAgropolitan:

MenujuSiasatBaruPerencanaan

Regional di Asia. Terjemahan. LembagaPenerbitFakultasEkonomi Universitas Indonesia (FE-UI). 


\section{LAMMPRAN}

\section{Lampiran 1}

\begin{tabular}{|c|c|c|c|c|}
\hline \multirow{2}{*}{ Variabel } & \multirow{2}{*}{ Sub Variabel } & \multicolumn{3}{|c|}{ Indikator (Bobot) } \\
\hline & & (1) & (2) & (3) \\
\hline \multirow{3}{*}{ Bahan Baku } & Asal Bahan Baku & $\begin{array}{l}\text { bahan baku } \\
\text { berasal dari luar } \\
\text { kawasan } \\
\text { Agropolitan }\end{array}$ & $\begin{array}{l}\text { bahan baku berasal dari } \\
\text { dalam kawasan } \\
\text { agropolitan, namun } \\
\text { tidak dalam satu } \\
\text { kecamatan dengan } \\
\text { lokasi agroindustri }\end{array}$ & $\begin{array}{l}\text { bahan baku berasal } \\
\text { dari dalam kawasan } \\
\text { agropolitan dan masih } \\
\text { dalam satu kecamatan } \\
\text { dengan lokasi } \\
\text { agroindustri }\end{array}$ \\
\hline & $\begin{array}{l}\text { Jarak asal bahan } \\
\text { baku }\end{array}$ & $>10 \mathrm{~km}$ & $5-10 \mathrm{~km}$ & $<5 \mathrm{~km}$ \\
\hline & $\begin{array}{l}\text { Cara } \\
\text { menghimpunbahan } \\
\text { baku }\end{array}$ & $\begin{array}{lr}\text { bahan } & \text { baku } \\
\text { dihimpun } & \text { dari } \\
\text { pedagang/ } & \\
\text { perantara di luar } \\
\text { kawasan } & \\
\text { agropolitan } & \\
\end{array}$ & $\begin{array}{l}\text { bahan baku dihimpun } \\
\text { dari pedagang/ } \\
\text { perantara di dalam } \\
\text { kawasan agropolitan }\end{array}$ & $\begin{array}{l}\text { bahan baku dihimpun } \\
\text { dari produsen asal } \\
\text { lokasi bahan baku } \\
\text { diperoleh }\end{array}$ \\
\hline \multirow{3}{*}{ TenagaKerja } & Jumlahtenagakerja & $<5$ orang & 5-19 orang & $>19$ orang \\
\hline & Asal Tenaga Kerja & $\begin{array}{lr}\text { tenaga } & \text { kerja } \\
\text { berasal dari luar } \\
\text { kawasan } \\
\text { agropolitan }\end{array}$ & $\begin{array}{lr}\text { tenaga kerja } & \text { berasal } \\
\text { dari dalam kawasan } & \text { kawn } \\
\text { agropolitan } & \text { namun } \\
\text { berbeda desa } & \\
\end{array}$ & $\begin{array}{l}\text { tenaga kerja berasal } \\
\text { dari dalam kawasan } \\
\text { agropolitan dan dalam } \\
\text { satu desa }\end{array}$ \\
\hline & $\begin{array}{l}\text { Jarak asal Tenaga } \\
\text { Kerja }\end{array}$ & $\begin{array}{l}\text { lebih dari rata-rata } \\
\text { jarak lokasi tenaga } \\
\text { kerja ke lokasi } \\
\text { agroindustri }\end{array}$ & $\begin{array}{l}\text { rata-rata jarak lokasi } \\
\text { tenaga kerja ke lokasi } \\
\text { agroindustri }\end{array}$ & $\begin{array}{lcr}\text { kurang } & \text { dari } & \text { rata-rata } \\
\text { jarak lokasi } & \text { tenaga } \\
\text { kerja } & \text { ke } & \text { lokasi } \\
\text { agroindustri } & \end{array}$ \\
\hline \multirow{3}{*}{ Pemasaran } & Lokasi Pasar & $\begin{array}{l}\text { berada di luar } \\
\text { kawasan } \\
\text { agropolitan } \\
\text { dengan wilayah } \\
\text { pemasaran kecil }\end{array}$ & $\begin{array}{lrr}\text { berada } & \text { di } & \text { dalam } \\
\text { kawasan } & \text { agropolitan } \\
\text { dengan } & \text { wilayah } \\
\text { pemasaran } & \text { kecil (lokal) }\end{array}$ & $\begin{array}{lrr}\text { berada } & \text { di } & \text { dalam } \\
\text { kawasan } & \text { agropolitan } \\
\text { dengan } & \text { wilayah } \\
\text { pemasran } & \text { luas } \\
\text { (regional) } & \\
\end{array}$ \\
\hline & Jarak lokasi pasar & $\begin{array}{l}\text { rata-rata jarak } \\
\text { pasar }>10 \mathrm{~km}\end{array}$ & $\begin{array}{l}\text { rata-rata jarak pasar 5- } \\
10 \mathrm{~km}\end{array}$ & $\begin{array}{l}\text { rata-rata jarak pasar < } \\
5 \mathrm{~km}\end{array}$ \\
\hline & $\begin{array}{l}\text { Cara distribusi } \\
\text { produk }\end{array}$ & $\begin{array}{l}\text { didistribusikan ke } \\
\text { pedagang lokasi } \\
\text { pemasaran di luar } \\
\text { Kawasan } \\
\text { Agropolitan }\end{array}$ & \begin{tabular}{ll}
\multicolumn{2}{l}{ didistribusikan ke } \\
konsumen di lokasi \\
pemasaran di luar \\
kawasan Agropolitan
\end{tabular} & $\begin{array}{l}\text { didistribusikan ke } \\
\text { konsumen di lokasi } \\
\text { pemasaran di dalam } \\
\text { kawasan Agropolitan }\end{array}$ \\
\hline \multirow{3}{*}{$\begin{array}{l}\text { Transportasi/ } \\
\text { Aksesibilitas }\end{array}$} & Jaringan jalan & $\begin{array}{l}\text { jalan non aspal } \\
\text { dengan lebar jalan } \\
<7 \text { meter }\end{array}$ & $\begin{array}{l}\text { jalan aspal dengan lebar } \\
<7 \text { meter }\end{array}$ & $\begin{array}{l}\text { jalan aspal dengan } \\
\text { lebar }>7 \mathrm{~m}\end{array}$ \\
\hline & $\begin{array}{l}\text { Biayatransportasi } \\
\text { (cost) }\end{array}$ & $\begin{array}{l}\text { biaya transportasi } \\
\text { (cost) lebih besar } \\
\text { dari rata-rata cost }\end{array}$ & $\begin{array}{l}\text { biaya transportasi (cost) } \\
\text { sama dengan rata-rata } \\
\text { cost }\end{array}$ & $\begin{array}{l}\text { biaya transportasi } \\
\text { (cost) lebih rendah } \\
\text { dari rata-rata cost }\end{array}$ \\
\hline & WaktuTempuh & $>1 \mathrm{jam}$ & $1 / 2-1$ jam & $<1 / 2$ jam \\
\hline \multirow{2}{*}{ FisikLahan } & Topografi & $>40 \%$ & $25-40 \%$ & $0-25 \%$ \\
\hline & RawanBencana & tidak aman & kurang aman & aman \\
\hline
\end{tabular}

Sumber: Olahan Penulis, 2015 


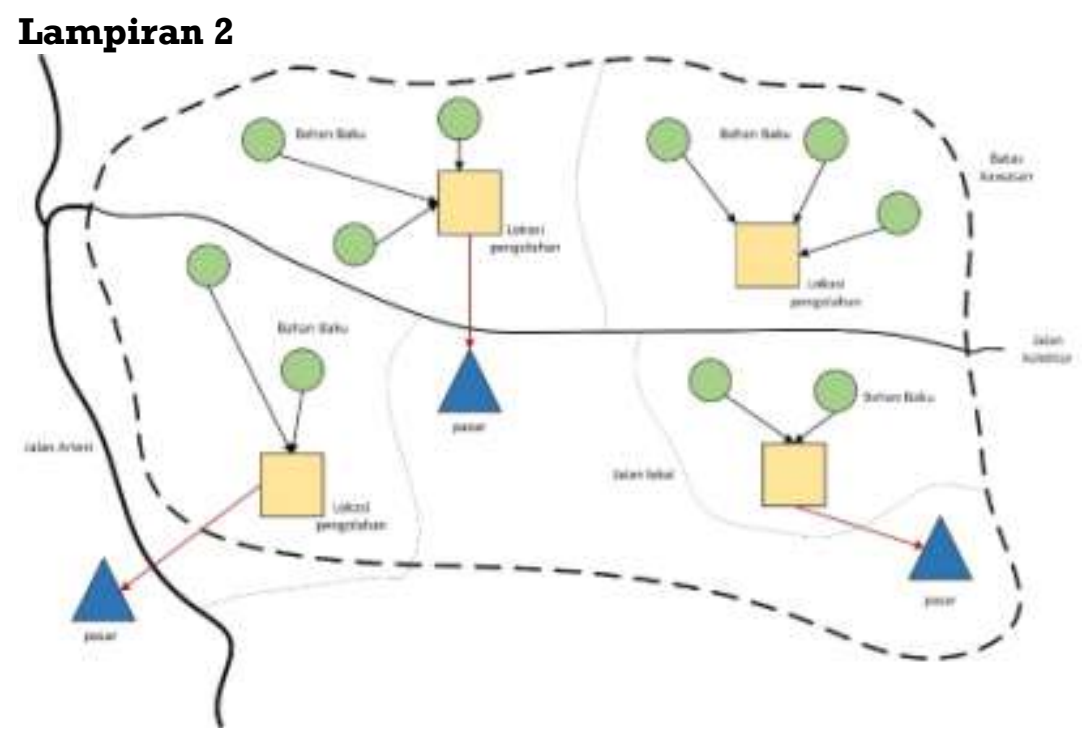

Gambar Struktur Ruang Agroindustri di Kawasan Agropolitan Sleman Sumber: Olahan Penulis, 2015 